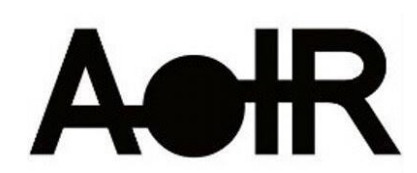

Selected Papers of \#AolR2019:

The $20^{\text {th }}$ Annual Conference of the

Association of Internet Researchers

Brisbane, Australia / 2-5 October 2019

\title{
TRUST IN TAIWAN'S MEDIA ECOLOGY, AUDIENCE AND CIVIC ENGAGEMENT: 2018 TAIWANESE LOCAL ELECTIONS AND NATIONAL REFERENDA AS A CASE STUDY
}

Pai-Lin Chen ${ }^{1}$, Yu-Chung Cheng ${ }^{1}$, Wen-Cheng Fu², Trisha T.C. Lin ${ }^{3}$

Organization(s): 1: National Chengchi University, Taiwan; 2: National Defense University, Taiwan; 3: National Chengchi University, Taiwan Institute for Governance and Communication Research

Submitted by: Prof. Yu-Chung Cheng (National Chengchi University, TW)

November 24, 2018 was the polling day for general local elections and national referenda in Taiwan. In the general local elections, the mayors of Taipei City and Kaohsiung were among the tightest, and the ruling and opposition parties geared up their campaign efforts as the polling approached. In the national referenda, same-sex marriage is the focal issue. As such, five out of the ten referenda were related this issue, so that the pro- and anti-same-sex marriage camps fervently lobbied for support.

This elections and referenda received a large-scale media coverage, but on the same time fake news circulating in the social media became a significant force in the elections and referenda, for the first time in the political history of Taiwan. Political figures were busy making clarification and accusing the opposing camps for releasing fake news. This triggered a crisis of trust in the entire society.

Therefore, this panel presents four papers aiming to examine the significance of this election and referendum to Taiwan from the perspectives of instant news, social media, the relationship between online and offline behaviors of citizens, and socially mediated activism. The authors explored media ecology, trust issues toward the audience and civic engagements of this election and referendum. The research methods of studies presented in this panel are also diverse, ranging from computational methods, national survey, to in-depth semi-structured interview.

The first paper analyzes instant news on the voting day and the following day in the five major online news media outlets in Taiwan. The primary goal of this study is to 
investigate how the online news media construct "liquid reality" in the election-related contents to earn the trust toward to media from the audience.

The second paper analyzes Twitter data related to the elections and referenda. By topic modeling, the large dataset was sorted into several topics. This approach allowed the identification of issues, in which "fake news" was in play during the elections. How social trust influence fake news sharing on social media was further discussed

The third paper concerns how the election-related information on social media influenced the offline behavior of the political participants. Specifically, the author conducted a nation-wide survey to examine the online political information consumption behavior, including news watching, online chat, comment posting, and the motivation to participate in real-life political activities. Also, the author explored how political trust constitutes a core contributor to this dynamic process.

The fourth study of the panel focuses on the same-sex marriage issue in the referenda. The relationship among socially mediated activism, fake news, and trust in social media are investigated. The author performed in-depth interviews with advocacy groups, thirdparty fact-checking organizations, governmental authorities, and social media platforms to explore the response strategies to the negative influence of fake news on social activism and vulnerable groups. 


\title{
EXPLORING "LIQUID REALITY" CONSTRUCTED BY ONLINE NEWS MEDIA: THE CASE STUDY OF 2018 LOCAL ELECTION IN TAIWAN
}

\author{
Pai-Lin Chen \\ National Chengchi University, Taiwan
}

"Liquidity" is the term used by the Polish scholar Zygmunt Bauman (2012) to refer to the significant characteristics of modern society such as uncertainty and variability. Liquid flows by spilling, inrushing, splashing, infiltrating, dripping, and etc. As constant changing of contexts is decisive, speed, rather than space, is decisive in our living world. This theory applied to many of our social structures, and the news media are part of it (Deuze, 2008).

The organization, production and delivery of news reflect the changing faces of the societies. In modern society, news media operate under a heavy-duty organization with rigid news production processes and long-standing paths to the delivery of contents (Fishman, 1980). For example, newspapers are constantly published every day. TV news launches every 2-4 hours. Tuchman (1978) uses the metaphor of web to describe how journalists weave the facts, and how these facts construct the reality of our society. On the other hands, news media in a liquid society owns flat organization, flexible production process, as well as virtual path in delivery news messages. These flat-and-light media produce their own version of facts like a steaming line. The facts emerge as time goes on. Online news media represent a good example of this liquid-like news production process.

Rather than its counterparts updating news in a solid, fixed pattern, the online news media distribute news in a different way (Deuze, 2007). Online news can be in different formats: text, images, video, graphics and even games (Widholm, 2016). The media coverage comes up with the development of the event, disregarding the traditional constraint of a fixed deadline (Karlsoon, 2012). As the social events go on, the media keep on covering news by adding texts and graphics, changing the bylines, reorganizing the formats, or restructuring the sequences of articles, a process of continuous editing (Karlsson \& Sjøvaag, 2016). All of these changing contents are operated under a temporal structure, rather than a spatial one.

Besides the format, routine, and platform, people in each society context have a different imagination toward the relationship between news and reality. In a traditional society, people regarded news as a mirror to reflect reality of the society. In a modern society, people regarded news as a media-constructed reality. In a liquid modern society, people tend to regard the reality as temporally flowing construction by the news media. This media constructed reality in a multiple format with speed and variability, and therefore can be titled "liquid reality".

Although it is nothing new to the notion that news owns one day of life. The accelerating speed in liquid society makes the life of news even shorter. Bauman noted that immorality is nothing but live-through-the-moment. For news media in contemporary society, reality may exist only through the moment, and it therefore owns the property of liquidity. One may ask: how do news media construct this liquid reality anyway? 
In this particular study, we tend to illustrating the notion of liquid reality by analyzing a case study of election news. Taiwan is an emerging democratic society in East Asia. Elections are one of the most significant social events in such society. Elections taking place every two years mobilize the whole society, take up a great deal of social resources, and attract most attention of the society. News media cover the elections with their full capacity, particularly during the days immediately before and after the election day. A large portion of news flow occurs in a very short period of time. This makes a case of instant news production and provide a significant research field with a highly-saturated amount of data. And therefore, this fits our intention to explore how online news media construct "liquid reality" in Taiwanese society.

We collected the news reports from the five major online media outlets in the 2018 local elections in Taiwan as the dataset of this case study. The dataset covers 72 hours amongst the election day, 8187 titles of online news. We compared and contrasted metadata and contents to illustrate how online media construct liquid reality in the election event. In essence, we explore the kind of formats, platforms and processes that online news media adopt to react with ever-changing news contexts, and the way they produce news flow in response to the unfolding events, in order to construct a liquid-like reality.

\section{References}

Bauman, Z. (2000). Liquid Modernity. New York: Polity.

Deuze, M. (2007) Journalism in liquid modern times, Journalism Studies, 8(4), 671-679.

Deuze, M. (2008). The changing context of news work: Liquid journalism and monitorial citizenship, International Journal of Communication, 2: 848-865.

Fishman, M. (1980). Manufacturing the News. Austin: The University of Texas Press.

Karlsoon, M. (2012). Charting the liquidity of online news. The International Communication Gazette, 74, 4, 385-402.

Karlsson, M. \& H. Sjøvaag (2016). Content analysis and online news: Epistemologies of analyzing the ephemeral web, Digital Journalism, 4(1): 177-192.

Tuchman, G. (1978). Making news: A study in the construction of reality. New York: Free Press.

Widholm, A. (2016). Tracing online news in motion, Digital Journalism, 4(1): 24-40. 


\section{COMPARING THE PATTERNS OF SHARING ON SOCIAL MEDIA BEWTEEN "TRUE NEWS" AND "FAKE NEWS": A CASE STUDY OF LOCAL ELECTIONS AND REFERENDA IN TAIWAN}

Yu-Chung Cheng

National Chengchi University, Taiwan

\section{Introduction}

Interactions between mass media and social media play a pivotal role in the formation of public opinions and affect the outcomes of political and electoral events in contemporary societies. When a major event breaks out, mass media publish real-time news as the event unfolds, and real-time news spreads rapidly through the social media; on the other hand, the sharing of and the comment on the news often once again became the subject of news coverage, so it forms a complex feedback network on social media, consisting of mass media, public figures, and general users.

Furthermore, the so-called "fake news" also enters this network. The clarifications and comments by public figures, political organizations, news media and netizens together form yet another network of disinformation and its counteractions on social media. The operation of this network often affects the public trust in the political candidates, and even the results of elections and referenda.

The 2018 Taiwanese local elections and referenda involves several complex topics, including the highly competitive Taipei and Kaohsiung mayoral elections and the controversial referenda on same-sex marriage. The disinformation attacks from one camp and the clarifications from the opposing camp were highly visible and were broadly discussed in the online community. Therefore, this represents an extraordinary case for studying how fake news spreads on social media.

This study analyzed the international and local news-sharing networks on Twitter. By computationally sorting tweets based on their topics, researchers can distinguish and contrast the patterns in which "true news" and "fake news" spreads on social media.

\section{Literature Review}

Chadwick (2013) pointed out that a hybrid media system has a profound impact on political communication. Political candidates use live broadcast on traditional mass media and on social media to promote and campaign, and this also increases the volume of discussion on social media in an election (Chadwick, O'Loughlin, \& Vaccari, 2017). The visit to online news is increasingly guided by links shared by individual users or by accounts operated by news media on social media. Consequently, gatewatching and news curation by social media users would have a greater impact on news diffusion and rumor correction than ever.

Social media users disseminate the "shareworthy" as well as the "newsworthy" to their own personal publics (Schmidt, 2014; Trilling et al., 2016; Bruns, 2018). However, not every social media user has the same ability or habit to perform fact-checking as the professional journalists do, and therefore the shareworthy information is not necessarily 
true. In so-called post-truth era, true news and fake news intermix, and discussions on social media are often confused and fail to distinguish the true from the false. Vosoughi, Roy, \& Aral (2018) found that fake news spread farther and faster, especially when such news concerns hate politics, which arouses negative emotions such as fear, resentment, and surprise. Susstein (2017) considered this as a crisis in democracy caused by social media, which split communities into echo chambers. Therefore, there is an urgent need to understand the spreading pattern of fake news versus that of true news on social media.

\section{Methodology}

We collected 38,617 unique tweets and 28,123 unique posting users by Twitter Search API using keywords "Taiwan election" and "Taiwan referendum" in Traditional Chinese, Simplified Chinese and English between November 14 and December 9, 2018 (total 25 days; voting took place in November 24, 2018). The average number of tweets per user is 1.37 .

Among the overall tweets, $77 \%$ are Chinese, $9 \%$ are Thai, $8 \%$ are English, and $6 \%$ are Japanese. Chinese posts includes those in different language codes, representing Taiwanese, Hong Kong, Chinese or overseas Chinese speakers. In order to explore the differences in the topics of interest between the different Chinese communities, we further selected the Chinese tweets for further analysis.

To identify the themes and contexts of the people's concerns in this event, we further explored individual topics discussed during the election period by natural language processing and topic modeling. Our topic modeling allowed us to identify and analyze the topics containing the "fake news" elements and generating a higher amount controversies during the election period.

\section{Result \& Discussion}

Our study found that the peak of the overall postings was on the voting day, resulting from the sharing of news reporting. The incumbent Taipei mayor Wenzhe Ke won by a small margin over the KMT candidate Shouzhong Ding, who subsequently file a lawsuit against the Central Election Commission as an attempt to invalidate the election result. This action caused extended discussion of this topic until November 28.

Through topic modeling analysis, it was found that the main topics distributed on the Twitter platform includes Taiwan election, democracy, President Ingwen Tsai, Democratic Progressive Party, election queuing, election invoicing, Taiwan-China relationship, Taiwan-China-USA relationship, Kaohsiung City Mayor Kuo-yu Han, and "greedy old people" (fake news).

Our results further showed that Twitter serves as a communication platform for transregional communities. The discussion on Taiwan's local elections focuses on the results, President Ing-wen Tsai and the ruling Democratic Progressive Party, as well as relations with China and US-China relations. However, there were also several popular "fake news" issues arising during the election period, including issues relating to the Kaohsiung Mayor 
Kuo-yu Han and Taipei Mayor's criticism of greedy old people. Both of these topics involve disinformation and rebuttals.

Within the specific topics selected, keywords were used to identify tweets, contents, and hyperlinks. Network relationships of all the posts participating in the discussion were reconstructed, so as to reveal the diffusion patterns of "true news" and "fake news" issues during the election period. Social trust toward accounts representing specific persona or institutions is revealed to a key catalyst in the suppression or facilitation of fake news sharing on social media.

\section{References}

Bruns, A. (2018). Gatewatching and news curation: Journalism, social media, and the public sphere. New York: Peter Lang.

Chadwick, A. (2013). The hybrid media system: Politics and power. Oxford, UK.: Oxford University Press.

Chadwick, A., O'Loughlin B., \& Vaccari, C. (2017). Why people dual screen political debates. Journal of Broadcasting and Electronic Media, 61(2), 220-239.

Schmidt, J.-H. (2014). "Twitter and the Rise of Personal Publics." In Katrin Weller, Axel Bruns, Jean Burgess, Merja Mahrt, and Cornelius Puschmann (eds.). Twitter and Society, pp. 3-17. New York: Peter Lang.

Sunstein, C. R. (2017). \#republic: divided democracy in the age of social media. New Jersey: Princeton University Press.

Trilling, D., Tolochko, P. \& Burscher, B. (2017). From newsworthiness to shareworthiness: How to predict news sharing based on article characteristics, Journalism \& Mass Communication Quarterly, 94(1), 38-60.

Vosoughi, S., Roy, D., \& Aral, S. (2018). The spread of true and false news online. Science, 359(6380), 1146-1151. 


\section{HOW DOES ONLINE SOCIAL MEDIA USING BEHAVIOR MOTIVATE OFFLINE POLITICAL PARTICIPATION? TAKING THE 2018 TAIWANSE LOCAL ELECTIONS AS A CASE STUDY}

Wen-Cheng Fu

National Defense University, Taiwan

\section{Introduction}

Social media is a growing force in the study of political participation. The focal facets for discussing the effects of new media range from the level of global media industries (Isaacs, 2014) to the level of personal media using behavior (Stier, Bleier, Lietz, \& Strohmaier, 2018). Accumulating evidences suggest that the political messages on vital social media platforms, such as the Facebook, Twitter, and Instagram influence the publics' cognitions, attitudes, and behavior toward the political engagements in the real worlds (Karlsen\& Enjolras, 2016; Hoffmann\& Suphan, 2017). However, fewer studies have specifically addressed how social media usage influences individuals' motivation toward engaging in political activities, such as protests, voting, and political mobilization.

14 million out of the 23 million Taiwanese are the Internet users (Xie, Liu, Wu, \& Tan, 2018). Social media, especially the Facebook and the PTT electronic message board, have become a significant resource for political information exchange among Taiwanese. It has become a commonplace to communicate with the audience via social media. The 2018 local elections of Taiwan were a critical election in which the landscape of traditional political parties was flipped (Anon., 2018). A focal points of this election was the important role of social media in motivating the publics' voting propensity (Holl, 2019). This study examines how the online media usage motivates the publics' offline political behavior in the 2018 Taiwanese local elections.

\section{Literature Review}

The theoretical framework of this study concerns the development of deliberative democracy. Specifically, media are a significant indicator of public opinion, and media can further influence the public opinion via the perceptions of opinion climate (Blekesaune, Elvestad, \& Aalberg, 2017). Also, media become the primary source from which the general public gains the knowledge about the governance of bureaucracy (Klinger \& Svensson, 2015). Further, new media, especially social media empowered the public. Social media users are not only information consumers but also information producers (Hoffmann \& Suphan, 2017). That is, the public can voice themselves up via social media without the censorship of the traditional media.

Also, this study examined the public's political trust toward the government which is another crux contributor to the offline political engagement of the public (Karlsen \& Enjolras, 2016). "Political trust" refers to the public's trust of that the political leaders will take all possible actions to safeguard the rights and interests of the general public rather than the interests of individuals (Stier, Bleier, Lietz, \& Strohmaier, 2018). Meanwhile, political trust is recognized as one of the vital factors that influence the public's perception and propensity on political activities in advance. 
This study also investigated the roles of social media agreement and attitude strength toward political activities as mediators to offline political participation (Klinger\& Svensson, 2015). Drawing on recent empirical analyses of online forms of political engagement, this study has identified three core interrelated research questions that literature on this topic needs to address. First, this study aimed at understanding how political participation in social media influences the publics' offline political participation. Second, how does political trust influence the publics' offline political participation? Third, how are online media usage and offline participation mediated by social media agreement and attitude strength of the public toward the political activities?

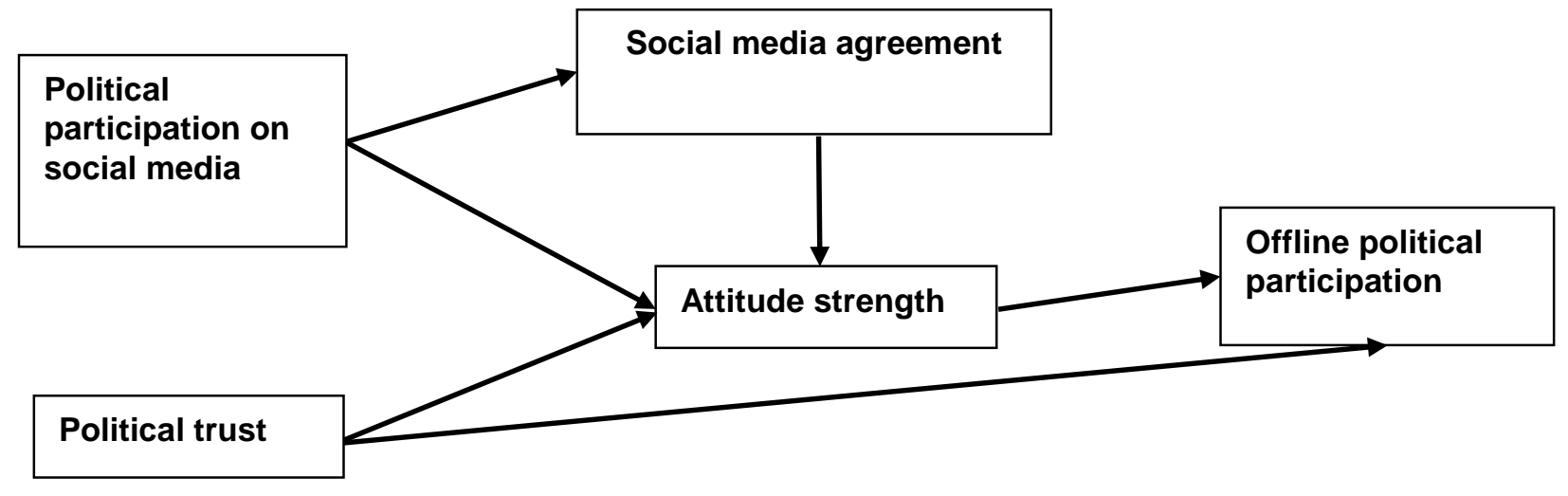

Figure 1. Construct of research

\section{Methodology}

For this study, a nationwide telephone survey was conducted by a Taipei-based commercial polling agency. Randomly generated phone numbers were used to reach Taiwanese over the age of 20 years old. 1,379 completed questionnaires were collected in about two weeks. Each participant spent about 20 minutes answering the questionnaire. The participants' ages ranged from 20 to 75 years.

The questionnaire contained measures for this study's key variables, including social media participation, political trust, social media agreement, attitude strength, offline political participation, and participants' demographics. All the measurement items were based on seven-point Likert scales, as these scales are reliable and valid, and have been widely used in previous studies (Yin \& Wang, 2014; Hoffmann \& Suphan, 2017).

Specifically, this survey questionnaire included seven online political activities on social media, divided into three levels, including the news attention, discussion, and the expressive levels; nine of campaign-specific offline political participation items were also conducted in this project, divided into three levels, including voting, party/campaign activity, protest activity, contacting, and communal levels.

\section{Result}

The results indicated that the frequency and dependency of online political engagement via social media correlate positively to the strength levels of attitude on political activities, as well as offline political participation. Specifically, the participants who had more 
experience in posting and commenting on political and campaign messages online are more likely to volunteer for a political party or candidate.

Besides, the political trust of the participants also positively correlates to the strength of attitude toward political participation. However, levels of social media agreement did not exhibit a significant correlation to offline political participation.

\section{Discussion}

This article has examined the concept and measurement of e-participation on social media and argued that a greater theoretical rigor is needed for the study of this phenomenon. In particular, by examining questions of how social media influence offline political participation behavior, this study suggested that online political participation is a key indicator of the audience's offline political participation.

More generally, the finding that the Internet may be spawning certain types of dominant, if not exclusive, forms of political activities is grounds for both concern and optimism. From a "digital divide" perspective, such a development carries the potential of reinforcing the existing participatory inequalities in that it may mean that the non-Internet users are excluded from this new form of citizen empowerment in Taiwan society.

\section{References}

Anon. (2018)Taiwan/Republic of China: Taiwan Ruling Party Suffers Major Defeat in Local Elections. Asia News Monitor, Asia News Monitor.

Blekesaune, A., Elvestad, E., \& Aalberg, T. (2012). Tuning out the world of news and current affairs: An empirical study of Europe's disconnected citizens. European Sociological Review, 28, 110-126.

Holl, D. (2019). Taiwan to Step Up Probe of Surveillance by Pro-China Media on Island. The Epoch Times, p. A12.

Hoffmann, C. P., \& Suphan, A. (2017). Stuck with "electronic brochures"? How boundary management strategies shape politicians' social media use. Information, Communication \& Society, 20(4), 551-569.

Isaacs, D. (2014). Social media and communication. Journal of Paediatrics and Child Health, 50(6), 421-422.

Karlsen, R., \& Enjolras, B. (2016). Styles of social media campaigning and influence in a hybrid political communication system: Linking candidate survey data with Twitter data. The International Journal of Press/Politics, 21(3), 338-357.

Klinger, U., \& Svensson, J. (2015). The emergence of network media logic in political communication: A theoretical approach. New Media \& Society, 17(5), 1241-1257.

Stier, S., Bleier, A., Lietz, H., \& Strohmaier, M. (2018). Election Campaigning on Social Media: Politicians, Audiences, and the Mediation of Political Communication on Facebook and Twitter. Political Communication, 35(1), 50-74.

Xie, Z., Liu, G., Wu, J., \& Tan, Y. (2018). Big data would not lie: Prediction of the 2016 Taiwan election via online heterogeneous information. EPJ Data Science,7(1), 116.

Yin, J., \& Wang, J. (2014). A Dirichlet multinomial mixture model-based approach for short text clustering. In Proceedings of the 20th ACM SIGKDD (pp. 233-242). New York, NY: ACM. 


\section{SAME-SEX MARRIAGE REFERENDUM IN TAIWAN: UNDERSTANDING SOCIALLY MEDIATED ACTIVISM, FAKE NEWS AND SOCIAL MEDIA TRUST}

Trisha T.C. Lin

National Chengchi University, Taiwan Institute for Governance and Communication Research

Taiwan has become the first Asian country to support the legalization of same-sex marriage in 2017. However, the revolutionary decision has led to societal polarization. Anti-gay groups mobilized millions of supporters and filed referenda to refute Supreme Court's ruling on marriage equality, while LGBT groups and the supporting communities urged to amend the civic code to allow gay couples to have all the rights entitled to heterosexual marriage (Yang, 2017). Before two sets of referenda were voted in late November 2018, the two opposing camps utilized online and social media to attract likeminded supporters and to persuade the neutral to support their causes. Unfortunately, lots of fake news that smeared the lifestyles of homosexual people with ill agenda has been disseminated virally via Facebook and Line for propaganda purposes, and they caused tension and conflicts in Taiwanese society.

This study aims to examine LGBT groups' mediated activism during the 2018 Taiwanese referenda for marriage equality. According to Waisbord (2018), mediated activism refers to the utilization of media technologies and institutional resources for collective action, including expressing demands, giving visibility to identities, raising awareness about social problems and solutions, petitioning authorities, and advocating for policy and legal changes. As mediated activism involves tactics, goals and platforms, social media has played an essential part in disseminating the information, disinformation and misinformation for both pro- and anti- marriage equality groups this time. Lots of fake news flooded on social media such as Facebook and Line, which not only confused voters but also affected their attitudes toward same-sex marriage, and even their voting behaviors.

Fake news is defined as the intentional production and dissemination of false information in order to deceive others (Klein \& Wueller, 2017; Tandoc, Zheng \& Ling, 2018). The most serious problem of the fake news during Taiwan's 2018 referenda was that it challenged the democratic policy-making process. On one hand, the misled people could not make informed decisions based on facts and rational debates; on the other hand, disinformation, primarily on social media, threatened the social trust and created polarization in Taiwanese society. Therefore, this paper aims to investigate LGBT groups' social media strategies to combat the fake news and to regain social trust during the 2018 Taiwanese elections.

As fake news and disinformation pose risk to socially mediated trust, the research question is that how do the LGBT organizations strategically deal with the risk that fake news poses to, in order to build, maintain and utilize social media trust to achieve social and political change? Given the influentialness and affordability of social media communication, activism groups had to make a good use of these 
platforms to frame issues, mobilize, and seek support. The LGBT groups tended not to have abundant resources and human power, in comparison with their counterparts. They faced concurrent challenges in promoting marriage equality rights and battling anti-LGBT disinformation. On the other hand, some fact-checking NGOs and authorities that felt concerned about negative impacts of anti-gay fake news made efforts to clarify the rumors and false accusation to LGBT communities, but fake news unfortunately outnumbered the verified ones. Hence, social media has been a two-faced sword for the mediated activism groups in the marriage equality referenda of Taiwan.

As the cost and the consequence of participating social movement is unsure, trust is an essential factor to overcome the uncertainty and anxiety between activists and between followers and the activism groups (Wang \& Emurian, 2005). As for socially mediated activism, Haciyakupoglu and Zhang (2015) have discussed how social trust (the feeling of connection to a certain social group or organization) and system trust (technological affordances) influenced the establishment and maintenance of mobilization among protestors. This study will adopt Haciyakupoglu and Zhang's framework to examine how LGBT groups strategize to combat fake news, to promote their causes, and to improve social trust during the referendum. This study utilizes snowball sampling to recruit key persons in LGBT groups, fact-check NGOs, and social media platforms for in-depth semi-structured interviews. By analyzing the transcribed data thematically, this study will be able to advance the theoretical understanding of socially mediated activism by untangling the complicated effects of fake news and social media trust, as well as shed light on the activism practices of using limited resources to overcome disinformation and fierce polarized perspectives.

\section{References}

Haciyakupoglu G. \& Zhang W. (2015). Social media and trust during the Gezi protests in Turkey. Journal of Computer-Mediated Communication, 20(4), 450-466. https://doi.org/10.1111/jcc4.12121

Klein, D. O., \& Wueller, J. R. (2017). Fake news: A legal perspective. Journal of Internet Law, 20(10), 1-13.

Tandoc, Jr. E.C., Zheng W. L. \& Ling R. (2018). Defining "Fake News". Digital Journalism, 6(2), 137-153, https://doi.org/10.1080/21670811.2017.1360143

Waisbord S. (2018). Revisited mediated activism. Sociology Compass, 12(6). https://doi.org/10.1111/soc4.12584

Wang Y. D. \& Emurian H. H. (2005). An overview of online trust: Concepts, elements, and implications. Computers in Human Behavior, 21(1), 105-125. https://doi.org/10.1016/j.chb.2003.11.008

Yang, W. (2018, February 15). Marriage equality in Taiwan: Time to re-engage the public. Retrieved from http://www.ketagalanmedia.com/2018/02/15/marriageequality-taiwan-time-re-engage-public/ 